\title{
The Influence of Parenting Patterns on the Personal Social Development of Preschool Children
}

\section{Sholahudin Ghozali1}

${ }^{1}$ Dukhan Medical Center Qatar Petroleum, Qatar

\section{Article Info}

Article History:
Accepted June 28th, 2020

Keywords:

Parenting style; Child stimulation; Preschool Age
Abstract

The child's personal social development is greatly influenced by the environment and interactions between the child and the parents or other adults around them. The type of parenting style of parents towards their children will affect the attainment of the level of education, social skills and overall development of the child. The purpose of this study was to determine the effect of parenting style on the personal social development of preschool children. The method used in this research is descriptive correlation method and cross-sectional approach. The respondents of this study were 39 parents who have preschool children aged 3-5 years in Dukhan Qatar. Sampling was taken by total sampling. The results showed that the parenting style of preschoolers affected the personal social development of preschoolers $(\mathrm{p}=$ 0.028). It is recommended that parents of preschool-age children provide more encouragement to their children in terms of independence and socializing with the environment.

\section{INTRODUCTION}

Childhood is a very important period because during this period a person's personality and attitudes are being formed. During this period the child shows the ability to move more activities, develop curiosity, and explore the surrounding environment. 1,2 The ability for wider social interaction and self-concept has also begun during this period. ${ }^{3}$ Optimal growth and development can be achieved if there is the interaction between children, parents and the surrounding environment where children interact socially.4,5 Children's social development is the stage of a child's ability to behave following environmental expectations. $^{2}$ One of the parameters of child development is social personality (social personality) which is related to the ability to be independent, socialize and interact with the environment. ${ }^{6}$

Parenting style is a combination of several elements that create a climate or emotional atmosphere in which parents communicate their attitudes towards their children. ${ }^{7}$ At preschool age, parenting patterns have more influence on children's ability to carry out activities and understanding of lessons. ${ }^{8}$ The results also state that the type of parenting style of parents towards their children will affect the attainment of education level, social skills and overall development of children. ${ }^{9}$ Parenting styles are classified into three types, namely:

Corresponding author:

Sholahudin Ghozali

sholahudin_ghozali@yahoo.com

South East Asia Nursing Research, Vol 2 No 2, June 2020

ISSN:2685-032X

DOI: https://doi.org/10.26714/seanr.2.2.2020.70-73 
Authoritarian, authoritative and permissive. ${ }^{10}$

Qatar society is very heterogeneous from various ethnic groups. Each of them has its own rules and culture. Therefore they will influence the adaptation process and social development of children. ${ }^{11}$ Based on the results of the preliminary study, it is known that in the Dukhan area 10 children aged 34 years 4 are less independent in terms of socializing with their surroundings. Like they still have to be watched by their parents to play with their playmates. The results of an interview with a teacher at Dukhan English School showed that some of the children in the Nursery did not want to play together with classmates of different ethnicities. This may be due to a lack of encouragement or parenting styles from parents in terms of socializing with new environments.

The purpose of this study was to determine the effect of parenting style on the personal social development of preschool children.

\section{METHODS}

This research has used a descriptive quantitative design. This study describes the parenting style and personal-social development of pre-school children. The approach that has been taken is a crosssectional approach. Measurement of children's upbringing and social personal development is measured at the same time.

The respondents of this research are parents who have pre-school age children. The inclusion criteria for research respondents included: residents of Dukhan and having children aged 3-5 years. Research respondents totalled 39 people. The sampling technique that has been used is a total sampling.

This research was conducted in the city of Dukhan, Qatar for one month starting from January 20, 2020, to February 20, 2020. The research was conducted by visiting the homes of each of the research respondents.

The instrument that has been used for data collection is a questionnaire. The questionnaire on indicators of parenting style has been adapted from instruments developed by Robinson, Mandleco, Olsen, and Hart. The instrument to determine children's development is the Denver Development Screening Test version II (DDST II).

Researchers have provided explanations to the research respondents before collecting data. The explanation contains the objectives, benefits, and consequences that must be carried out during the research. The involvement of research respondents was voluntary and without coercion from the researcher. After the respondent agreed, he was asked to sign an informed consent sheet. Researchers have given rewards to respondents in the form of souvenirs. Researchers maintain the confidentiality of research subjects by not including the respondent's name on the research report.

The data from the research results were analyzed using the Chi-Square test and Fisher's exact test to determine the influence of parenting styles on children's social development.

\section{RESULTS}

The results showed that the mean age of the respondents was 37.44 years with a standard deviation of 4.42 . The youngest was 26 years old, while the oldest was 48 years old. The education level of the most respondents is diploma level as many as 15 people (38.5\%), the remaining 14 respondents have a bachelor degree (35.9\%) and at least 10 people have high school education (25.6\%). The average length of a marriage of respondents' parents with pre-school children in Dukhan Qatar is 10.03 years with a standard deviation of 
4.094. The longest marriage is 20 years, while the fastest is 4 years.

The results of research on the type of parenting style of Indonesian preschoolaged parents in Dukhan Qatar, it is known that most of the respondents have Authoritative parenting types, namely 37 respondents (94.9\%). The study also showed that only 2 respondents had the permissive parenting type (5.1\%) and there were no respondents who had the Authoritarian parenting type.
The results of the study on children's personal social development showed that there were 32 children (82.1\%) whose social personal development was normal, and only 7 children (17.9\%) had less social personal development.

The results of the bivariate analysis in this study showed that as many as 2 parents (4.4\%), with the permissive parenting type, had children with less social personal development. As 32 parents (82.1\%) with authoritative parenting type had children with normal social personal development.

Table 1

The relationship between parenting style and children's personal social development

\begin{tabular}{|c|c|c|c|c|c|c|}
\hline \multirow{3}{*}{ Indicators } & \multicolumn{4}{|c|}{$\begin{array}{c}\text { Children's personal social } \\
\text { development }\end{array}$} & \multirow[t]{3}{*}{$\begin{array}{c}\text { Coefficient } \\
\text { (95\% CI) }\end{array}$} & \multirow[t]{3}{*}{$p$} \\
\hline & \multicolumn{2}{|c|}{ Less } & \multicolumn{2}{|c|}{ Pass } & & \\
\hline & $\mathrm{f}$ & $\%$ & $f$ & $\%$ & & \\
\hline $\begin{array}{l}\text { Parenting Patterns } \\
\text { Permissive } \\
\text { Authoritative }\end{array}$ & $\begin{array}{l}2 \\
5\end{array}$ & $\begin{array}{c}4.4 \\
13.5\end{array}$ & $\begin{array}{c}0 \\
32\end{array}$ & $\begin{array}{c}0 \\
82.1\end{array}$ & $\begin{array}{c}0.135 \\
(0.060-0.305)\end{array}$ & 0.028 \\
\hline
\end{tabular}

\section{DISCUSSION}

The results showed that there was a significant effect of parenting styles on the personal social development of pre-school children. The results of this study are supported by the results of other studies that the type of parenting style of parents towards their children will affect the attainment of education level, social skills and overall development of children. This study also shows that few parents with the permissive parenting type have children with less social personal development. And more parents with the authoritative parenting type have children with normal social personal development. This result is different from previous research which explains that authoritative parenting style is not related to pre-school prosocial behavior. $^{12}$

This shows that authoritative parenting is good parenting. This type of parenting, parents try to direct their children rationally and appreciate communication that gives and takes each other and directs the child to be independent so that it will help the child's personal social development in a positive direction. Meanwhile, permissive parenting parents tend to allow children to regulate their own activities, do not control and are not trained to be responsible, even though preschoolers should be introduced to good and bad norms so that if parents allow children too much it will affect personal social development in a negative direction. ${ }^{10}$ Parents who use authoritative parenting have higher emotional regulation than parents who use permissive parenting. ${ }^{13}$ The results of other studies have shown that parenting styles for tau people can affect children's mental health and self-esteem. ${ }^{14}$

The results of other studies show that authoritative parenting is able to enhance one's personal growth initiatives. ${ }^{15}$ Another study suggests that the most beneficial parents (with authoritative parenting) are people high in extraversion, openness to experience, and awareness, and low in neuroticism. ${ }^{16}$ Good parenting can affect a child's ability to communicate with others. ${ }^{17}$ 


\section{CONCLUSION}

Parents' parenting influences the personal social development of pre-school children in Dukhan Qatar. Authoritative parenting styles are better at stimulating pre-school children's personal social development. Researchers suggest especially for the Indonesian people in Qatar dukhan to be able to use proper parenting in caring for children, one of which is by implementing autoritative parenting to optimize children's social development. In addition, it is hoped that parents will give more encouragement to preschool children in terms of independence and socializing with a multinationality environment by participating in community activities that involve the entire community of Dukhan residents.

\section{ACKNOWLEDGMENTS}

We would like to thank all respondents who were willing to be involved in this research. and to all those who have helped complete this research.

\section{CONFLICTS OF INTEREST}

Neither of the authors has any conflicts of interest that would bias the findings presented here.

\section{REFERENCES}

1. Wilson MHCRD. Wong's Essentials of Pediatric Nursing. Tenth Edit. Elsevier Health Sciences; 2016.

2. Little SG, Swangler J, Akin-Little A. Defining social skills. In: Handbook of Social Behavior and Skills in Children. Springer; 2017:9-17.

3. Meadow KP. Deafness and Child Development. University of California Press; 2020.

4. Maleki M, Chehrzad MM, Kazemnezhad Leyli E, Mardani A, Vaismoradi M. Social skills in preschool children from teachers' perspectives. Children. 2019;6(5):64.

5. Maleki M, Mardani A, Mitra Chehrzad M,
Dianatinasab M, Vaismoradi M. Social skills in children at home and in preschool. Behav Sci (Basel). 2019;9(7):74.

6. Legkauskas V, Magelinskaite-Legkauskiene S. Importance of social competence at the start of elementary school for adjustment indicators a year later. Issues Educ Res. 2019;29(4):12621276.

7. Elliott L, Bachman HJ. How do parents foster young children's math skills? Child Dev Perspect. 2018;12(1):16-21.

8. Ling J, Robbins LB, Wen F, Zhang N. Lifestyle interventions in preschool children: a metaanalysis of effectiveness. Am J Prev Med. 2017;53(1):102-112.

9. Garcia OF, Serra E. Raising children with poor school performance: Parenting styles and short-and long-term consequences for adolescent and adult development. Int J Environ Res Public Health. 2019;16(7):1089.

10. Kuppens S, Ceulemans E. Parenting styles: A closer look at a well-known concept. J Child Fam Stud. 2019;28(1):168-181.

11. Strand PS, Vossen JJ, Savage E. Culture and child attachment patterns: A behavioral systems synthesis. Perspect Behav Sci. 2019;42(4):835850.

12. Arifiyanti N. Relationship between Authoritative Parenting Style and Preschools Prosocial Behavior. J Obs J Pendidik Anak Usia Dini. 2019;3(2):311-319.

13. Bahrami B, Dolatshahi B, Pourshahbaz A, Mohammadkhani P. Parenting style and emotion regulation in mothers of preschool children. Pract Clin Psychol. 2018;6(1):3-8.

14. Singh S. Parenting style in relation to children's mental health and self-esteem: A review of literature. Indian J Heal Wellbeing. 2017;8(12).

15. Hirata H, Kamakura T. The effects of parenting styles on each personal growth initiative and self-esteem among Japanese university students. Int J Adolesc Youth. 2018;23(3):325333.

16. Bahrami B, Dolatshahi B, Pourshahbaz A, Mohammadkhani P. Comparison of personality among mothers with different parenting styles. Iran J Psychiatry. 2018;13(3):200.

17. Bingham GE, Jeon $\mathrm{H}$, Kwon K, Lim C. Parenting styles and home literacy opportunities: Associations with children's oral language skills. Infant Child Dev. 2017;26(5):e2020. 